\title{
3 Researc Square

\section{An Integrated Liquid Approach To The Synthesis of CdSxSe1-x@ZrSiO4 Ceramic Pigments For Commercial Ink-Jet Printing}

Huafeng LIU

Jiangxi Jinhuan Pigments Co., Ltd

Xiaojun Zeng ( $\nabla$ zengxiaojun@jci.edu.cn )

Jingdezhen Ceramic Institute https://orcid.org/0000-0001-5729-1361

Xiaozhen ZHANG

Jingdezhen Ceramic Institute

Runyuan LIU

Jiangxi Jinhuan Pigments Co., Ltd

Wei LIU

Jiangxi Jinhuan Pigments Co., Ltd

Renhua CHEN

Jiangxi Jinhuan Pigments Co., Ltd

Qibing CHANG

Jingdezhen Ceramic Institute

\section{Research Article}

Keywords: CdSxSe1-x@ZrSiO4 pigments, Ceramic ink-jet printing, Bright red hue, Wear-resistant, Particle size

Posted Date: May 5th, 2021

DOI: https://doi.org/10.21203/rs.3.rs-479432/v1

License: (c) (1) This work is licensed under a Creative Commons Attribution 4.0 International License. Read Full License 


\section{Abstract}

Cadmium selenide sulfide ( $\left.\mathrm{CdS}_{x} \mathrm{Se}_{1-x}\right)$ encapsulated by zirconium silicate $\left(\mathrm{ZrSiO}_{4}\right)\left(\mathrm{CdS}_{\mathrm{x}} \mathrm{Se}_{1-\mathrm{x}} @ \mathrm{ZrSiO}_{4}\right)$ has been widely considered in ceramic pigments for ink-jet printing but suffer from big particle size and dark hue troubles. Herein, an integrated liquid approach was developed, which gives $\mathrm{CdS}_{\mathrm{x}} \mathrm{Se}_{1-\mathrm{x}} @ \mathrm{ZrSiO}_{4}$ pigment a uniform size, bright and pure red hue, and good wear resistance. This new strategy can effectively control the grain size of the encapsulated pigment from the dispersibility of the sol system, the ratio of material, the sintering conditions, and the selection of raw materials. The developed pigment has been successfully used in ink-jet printing and commercialized. This study paves an integrated liquid approach to improve the compatibility of wear-resistant and bright red $\mathrm{CdS}_{\mathrm{x}} \mathrm{Se}_{1-\mathrm{x}} @ \mathrm{ZrSiO}_{4}$ pigments in ceramic ink-jet printing.

\section{Introduction}

Recently, ink-jet printing technology has gradually matured and has been applied to the ceramic industry [1-3]. However, due to the limitation of inorganic pigments, the colors of printed products are still not rich enough, especially the bright and pure red inks are always blank [4], and only Fe-Cr-Zn brown-red pigments or Zr-Fe red pigments (dark red) can barely be used to adjust the color $[5,6]$. Thus, researchers can only greatly reduce the use of red color from design sources, but this greatly limits the design and effect of ink-jet patterns. To this end, it is highly desirable to develop bright and pure red inks for ceramic ink-jet printing, which however remains a big challenge.

Notely, cadmium selenide sulfide $\left(\mathrm{CdS}_{\mathrm{x}} \mathrm{Se}_{1-\mathrm{x}}\right)$ encapsulated by zirconium silicate $\left(\mathrm{ZrSiO}_{4}\right)$ $\left(\mathrm{CdS}_{\mathrm{x}} \mathrm{Se}_{1-\mathrm{x}} @ \mathrm{ZrSiO}_{4}\right)$ red pigment has a bright red hue [7], and its red hue can be tuned by the amount of selenium. At present, no pigment can achieve such a red hue in the glaze. There are also some encapsulated pigments have been reported, such as encapsulated cobalt blue [8], carbon black encapsulated by $\mathrm{ZrSiO}_{4}$ [9-11], cerium sulfide red coating [12-14], $\mathrm{Fe}_{2} \mathrm{O}_{3}-\mathrm{ZrSiO}_{4}-\mathrm{SiO}_{2}$ [15], and $\mathrm{Fe}_{2} \mathrm{O}_{3} @ \mathrm{SiO}_{2}$ [16]. Unfortunately, the coating system, preparation process, and application effect of these pigments are quite different from that of $\mathrm{CdS}_{\mathrm{x}} \mathrm{Se}_{1-\mathrm{x}} @ \mathrm{ZrSiO}_{4}$ pigment, which is of little reference.

$\mathrm{CdS}_{\mathrm{x}} \mathrm{Se}_{1-\mathrm{x}} @ \mathrm{ZrSiO}_{4}$ pigment prepared by the traditional process cannot be used for ink-jet printing. This is because the red hue will fade to white within the required particle size range (D50 $=500 \pm 200 \mathrm{~nm}$, D100 $\leq 1.5 \mu \mathrm{m}$ ) of ink-jet printing. In additional, when the size of pigment is mechanically refined to $\sim 1.2 \mu \mathrm{m}$ (D50), the structure of pigment is mostly destroyed, and the red hue is basically disappeared.

The structure of $\mathrm{CdS}_{\mathrm{x}} \mathrm{Se}_{1-\mathrm{x}} @ \mathrm{ZrSiO}_{4}$ pigment is formed by a crystal cavity mechanism. Generally, the effective chromogenic grain size of the traditional encapsulated pigment is larger than $3 \mu \mathrm{m}$, and the larger the grain size, the stronger the chromogenic ability. Its wear resistance is far less than that of spinel-based pigments or ion-doped pigments $[17,18]$. Therefore, to use the encapsulated pigment as a ceramic ink, the crystal particle of pigment needs to be further refined, and the original grain should be controlled at the nanoscale and have better dispersibility. 
In this work, we develop an integrated liquid approach of bright and pure red $\mathrm{CdS}_{\mathrm{x}} \mathrm{Se}_{1-\mathrm{x}} @ \mathrm{ZrSiO}_{4}$ pigment with uniform size and good wear resistance by the optimization of material ration, solvent system, and process parameters. Excitingly, the developed pigment has been successfully commercialized. This study paves an efficient strategy to improve the compatibility of wear-resistant $\mathrm{CdS}_{\mathrm{x}} \mathrm{Se}_{1-\mathrm{x}} @ \mathrm{ZrSiO}{ }_{4}$ pigment for ceramic ink-jet printing.

\section{Experiment}

\subsection{Preparation of the pigments}

$200 \mathrm{~g}$ of zirconium oxychloride $\left(\mathrm{ZrOCl}_{2} \cdot 8 \mathrm{H}_{2} \mathrm{O}, 99 \%\right.$ purity, Guangdong Orient Zirconic Ind Sci \& Tech Co., Ltd.) and $42.9 \mathrm{~g}$ of cadmium sulfate ( $\mathrm{CdSO}_{4} \cdot 8 / 3 \mathrm{H}_{2} \mathrm{O}, 99 \%$ purity, Aladdin) were dissolved in $1000 \mathrm{~mL}$ distilled water and recorded as solution A. $70.8 \mathrm{~g}$ of sodium sulfide $\left(\mathrm{Na}_{2} \mathrm{~S} \cdot 9 \mathrm{H}_{2} \mathrm{O}, 99 \%\right.$ purity, Aladdin), $37 \mathrm{~g}$ of sodium hydroxide ( $\mathrm{NaOH}, 95 \%$ purity, Aladdin) and $4.7 \mathrm{~g}$ of selenium powder (Se, $99.8 \%$ purity, Mitsubishi Chemical Holdings) were dissolved in $1000 \mathrm{~mL}$ distilled water, heated to boiling, and then cooled (solution B). $5 \mathrm{~mL}$ of monoethanolamine $\left(\mathrm{HO}\left(\mathrm{CH}_{2}\right)_{2} \mathrm{NH}_{2}, 99.5 \%\right.$ purity, Aladdin) and $0.5 \mathrm{~g}$ of hyper dispersant (Solsperse 27000, The Lubrizol Corporation)in $2000 \mathrm{~mL}$ of distilled water were marked as solution C. $130 \mathrm{~g}$ of sodium metasilicate $\left(\mathrm{Na}_{2} \mathrm{SiO}_{3} \cdot 5 \mathrm{H}_{2} \mathrm{O}, 99 \%\right.$ purity, Aladdin) was dissolved in $1000 \mathrm{~mL}$ of distilled water, heated to boiling, and then cooled (solution D). $51.2 \mathrm{~g}$ of concentrated sulfuric acid $\left(\mathrm{H}_{2} \mathrm{SO}_{4}, 98 \mathrm{wt} \%\right.$, Sinopharm) was dissolved in $1000 \mathrm{~mL}$ of distilled water and recorded as solution $\mathrm{E}$.

Solution A and B were dropped into solution $C$ and keep stirring at $450 \mathrm{r} \mathrm{min}^{-1}$. After stirring for $20 \mathrm{~min}$, solution $M$ was obtained. Then solution $D$ and $E$ were dropped into solution $M$ at the same time and keep stirring (450 $\left.\mathrm{r} \mathrm{min}^{-1}\right)$. After stirring for $60 \mathrm{~min}$, the product was filtered and washed and then dried to obtain a bulk. The bulk was crushed and mixed with $7 \mathrm{wt} \%$ lithium fluoride (LiF, 99.9\% purity, Sinopharm), and then loaded into the crucible. After calcination at $900{ }^{\circ} \mathrm{C}$ for $30 \mathrm{~min}$, the powder was soaked in acid for $3 \mathrm{~h}$, then washed with distilled water and dried in a vacuum at $60^{\circ} \mathrm{C}$ for $12 \mathrm{~h}$ to obtain bright red pigment $\mathrm{R}_{1}$.

The preparation process of yellow pigment $R_{2}$ is similar to that of red pigment $R_{1}$. The difference is that 2 $\mathrm{g}$ of zinc chloride $\left(\mathrm{ZnCl}_{2}, 99 \%\right.$ purity, Aladdin) is added to solution $\mathrm{A}$, selenium powder is removed from solution $\mathrm{B}$, and the content of sodium sulfide is $72.8 \mathrm{~g}$.

For comparison, red-brown pigment $\mathrm{J}_{1}(\mathrm{Fe}-\mathrm{Cr}-\mathrm{Zn})$ and gold-brown pigment $\mathrm{J}_{2}(\mathrm{Fe}-\mathrm{Cr}-\mathrm{Zn})$ are the current commercial pigments for ink-jet printing. The red pigment $\mathrm{T}_{1}\left(\mathrm{CdS}_{\mathrm{x}} \mathrm{Se}_{1_{-}} \mathrm{x} @ \mathrm{ZrSiO}{ }_{4}\right)$ and yellow pigment $\mathrm{T}_{2}$ (CdS@ZrSiO$\left.{ }_{4}\right)$ were prepared by the traditional process [19].

\subsection{Preparation of ceramic ink and ink-jet ceramic tile}

The detailed formulation of the ink is shown in Table 1. After filling the raw materials into the ball mill, the particle size is ball milled (zirconium ball, diameter of $0.3 \sim 0.4 \mathrm{~mm}$ ) to $D_{50}$ about $600 \mathrm{~nm}, \mathrm{D}_{100}$ about 
$1250 \mathrm{~nm}$, and the slurry viscosity is controlled at $\sim 20 \mathrm{cp}$. The fabrication of ink-jet tile is as follows: using an ink-jet printer to painted the inks $I_{1}, I_{2}, I_{3}$, and $I_{4}$ into color blocks with different gray levels on the sintered white tiles, and then printing a layer of glaze. After drying, it was calcined at $1200{ }^{\circ} \mathrm{C}$ to achieve a contrast pattern of the ink-jet paint.

Table 1

Components of ink $I_{1}, I_{2}, I_{3}$, and $I_{4}$.

\begin{tabular}{|llll|}
\hline Ink cod & Pigment & Solvent & Dispersant \\
\hline $\mathrm{I}_{1}$ & $\mathrm{R}_{1} 40 \%$ & $50 \%$ & $10 \%$ \\
\hline $\mathrm{I}_{2}$ & $\mathrm{R}_{2} 40 \%$ & $50 \%$ & $10 \%$ \\
\hline $\mathrm{I}_{3}$ & $\mathrm{~J}_{1} 40 \%$ & $50 \%$ & $10 \%$ \\
\hline $\mathrm{I}_{4}$ & $\mathrm{~J}_{2} 40 \%$ & $50 \%$ & $10 \%$ \\
\hline $\begin{array}{l}\text { Note: } \mathrm{R}_{1} \text { and } \mathrm{R}_{2} \text { are the red and yellow pigments obtained in this study. } \mathrm{J}_{1} \text { (red-brown, Fe-Cr-Zn) and } \\
\mathrm{J}_{2} \text { (gold-brown, Fe-Cr-Zn) are the commercial pigments. }\end{array}$ \\
\hline
\end{tabular}

\section{Results And Discussion}

To evaluate the features of red pigment $R_{1}$ and yellow pigment $R_{2}$ prepared by this new strategy, the red pigment $T_{1}$ and yellow pigment $T_{2}$ prepared by the traditional process are compared [19]. All these ceramic pigments are $\mathrm{CdS}_{\mathrm{x}} \mathrm{Se}_{1-\mathrm{x}}$ encapsulated by $\mathrm{ZrSiO}_{4}$. X-ray diffraction (XRD) was performed to detect the crystal phases of the red pigments $R_{1}$ and $T_{1}$. Obviously, both of them are composed of the main $\mathrm{ZrSiO}_{4}$ phase, a small amount of $\mathrm{CdS}_{\mathrm{x}} \mathrm{Se}_{1-\mathrm{x}}$ phase, and a few $\mathrm{SiO}_{2}$ phases (Fig. 1). Furthermore, the diffraction peak of $\mathrm{CdS}_{x} \mathrm{Se}_{1-x}$ phase is weak due to the inclusion layer of $\mathrm{ZrSiO}_{4}$ crystal. The high purity of $\mathrm{ZrSiO}_{4}$ and $\mathrm{CdS}_{x} \mathrm{Se}_{1-x}$ phases indicates the feasibility of this new preparation strategy.

As expected, the red pigment $\mathrm{R}_{1}$ and yellow pigment $\mathrm{R}_{2}$ used for ink-jet printing are brighter and purer than the red-brown pigment $J_{1}$ and gold-brown pigment $J_{2}$ used for commercial ink-jet printing (Fig. 2). Although the tones of the red pigment $T_{1}$ and the yellow pigment $T_{2}$ show better effects in brightness and purity, they can only be used in traditional technology due to their big particle size. In order to resist the erosion of high-temperature glaze, traditional inclusion pigments require a thicker $\mathrm{ZrSiO}_{4}$ coating layer. Therefore, using a higher calcination temperature makes the $\mathrm{ZrSiO}_{4}$ crystals have better crystallinity and larger grains, and the encapsulated $\mathrm{CdS}_{\mathrm{x}} \mathrm{Se}_{1-\mathrm{x}}$ particles are fully converted into crystals, and finally show a brighter hue.

The crystal composition (Fe-Cr-Zn) and structure of the pigments $J_{1}$ and $J_{2}$ determine that their hues are not bright enough for ink-jet printing. The tiles that painted the inks $I_{1}\left(R_{1}\right), I_{2}\left(R_{2}\right), I_{3}\left(J_{1}\right)$, and $I_{4}\left(J_{2}\right)$ are shown in Fig. 3. The corresponding CIE Lab chromaticity values are displayed in Table 2. For the red 
pigment, the redness value $\left(a^{*}\right)$ of $R_{1}$ is 30.66 , while the value $a^{*}$ of $J_{1}$ is only 18.37 . Therefore, the pigment $J_{1}$ cannot present more colors when designing the ink-jet pattern. Thus, the replacement of pigment $\mathrm{J}_{1}$ by pigment $\mathrm{R}_{1}$ can meet most of the needs for red color matching, and the color range is greatly expanded. Meantime, the tone of pigment $\mathrm{R}_{2}$ is very close to that of praseodymium doped zircon yellow pigment for ink-jet, and the color intensity of the ink with the same solid content prepared by pigment $\mathrm{R}_{2}$ is almost twice that of the ink prepared by praseodymium doped zircon yellow pigment. It is expected that praseodymium zircon doped yellow pigment for ink-jet will gradually be replaced by pigment $\mathrm{R}_{2}$.

Table 2

Chromaticity values of ink $I_{1}, I_{2}, I_{3}$, and $\mathrm{I}_{4}$ after firing.

\begin{tabular}{|llll|}
\hline Ink & $L^{*}$ & $a^{*}$ & $b^{*}$ \\
\hline $\mathrm{I}_{1}\left(\mathrm{R}_{1}\right)$ & 62.68 & 30.66 & 22.54 \\
\hline $\mathrm{I}_{2}\left(\mathrm{R}_{2}\right)$ & 84.97 & -0.17 & 48.05 \\
\hline $\mathrm{I}_{3}\left(\mathrm{~J}_{1}\right)$ & 60.15 & 18.37 & 28.65 \\
\hline $\mathrm{I}_{4}\left(\mathrm{~J}_{2}\right)$ & 47.81 & 14.31 & 15.61 \\
\hline
\end{tabular}

Compared with the traditional inclusion pigments $T_{1}$ and $T_{2}(D 50=6.5 \mu \mathrm{m}, \mathrm{D} 97=16 \mu \mathrm{m})$, the as-prepared pigments $R_{1}$ and $R_{2}(D 50=1.1 \mu \mathrm{m}, \mathrm{D} 97=2.5 \mu \mathrm{m})$ have a small particle size and a narrow distribution, as shown in Fig. 4. In the process of ink grinding, as the crystal grains are broken and refined, the color decay of pigments $R_{1}$ and $R_{2}$ is much smaller than that of pigments $T_{1}$ and $T_{2}$, which also suggests that pigments $R_{1}$ and $R_{2}$ are more wear-resistant. When the pigments $R_{1}$ and $R_{2}$ are ground to $D 50=0.6 \mu \mathrm{m}$, the appearance of the ink still has a good color, and their color only fades by $30 \%$. The coring intensity of the ink prepared by pigments $R_{1}$ and $R_{2}$ and its irreplaceable pure tone has great commercial value in ceramic ink at present. When the pigments $T_{1}$ and $T_{2}$ are ground to $D 50=1.2 \mu \mathrm{m}$, the appearance color fades by $60 \%$, and the color fades by almost $100 \%$ after ink-jet printing and firing. This is because after the crystal grains are broken, the $\mathrm{ZrSiO}_{4}$ cannot completely encapsulate the $\mathrm{CdS}_{\mathrm{x}} \mathrm{Se}_{1-\mathrm{x}}$, and the exposed $\mathrm{CdS}_{\mathrm{x}} \mathrm{Se}_{1-\mathrm{x}}$ will be decomposed into cadmium oxide, selenium oxide, and sulfur dioxide under high temperature. If soaking with strong acid at this time, the color will fade away completely. Therefore, under the particle size requirements of ceramic ink (solid particle size in the ink: D50 $=500 \pm 200 \mathrm{~nm}, \mathrm{D} 100 \leq$ $1.5 \mu \mathrm{m}$ ), the pigments $T_{1}$ and $T_{2}$ have not been successfully used in ink-jet printing, although they have incomparable bright colors.

Based on the scanning electron microscope (SEM), the grain size of pigment $R_{1}$ is uniform, basically between $200 \sim 1000 \mathrm{~nm}$, which is close to the particle size required for the ink (Fig. 5a,b). This result is consistent with the size distribution result above. Only about $15 \%$ of the grains need to be further refined, 
so the grinding time required for grinding the ink is relatively shorter. The microstructure of pigment $R_{2}$ is similar to that of pigment $\mathrm{R}_{1}$ due to the similar preparation process. The appropriate size of the grinding ball should be selected to avoid the particles that have reached the particle size requirements from being destroyed again, which can protect the hue of the pigment to a great extent. Compared with the pigments $T_{1}$ and $T_{2}$ prepared by the traditional process (Fig. $5 c, d$ ), the grain size of pigments $R_{1}$ and $R_{2}$ is significantly reduced and the grains have no obvious acid etch holes. The developed synthesis strategy optimizes the ratio of $\mathrm{ZrSiO}_{4}$ and $\mathrm{CdS}_{x} \mathrm{Se}_{1-x}$, and reduces the firing temperature and holding time, which reduces the growth speed of the coating layer crystals and the chromogenic crystals, so as to achieve the purpose of controlling the grain size of the pigment. Although the color strength and temperature resistance of the pigments prepared by this process are slightly weakened in the glazing system, which is no advantage in the traditional application field, yet it has better resistance and finer grain, which can meet the requirements of ink-jet pigment.

The microstructure of the prepared pigment $R_{1}$ was observed by transmission electron microscope (TEM), as shown in Fig. $6 a, b$. The $\mathrm{ZrSiO}_{4}$ layer is very complete, and the coated $\mathrm{CdS}_{x} \mathrm{Se}_{1-x}$ chromogenic grains are spherical and uniformly dispersed, with a particle size of $20 \sim 50 \mathrm{~nm}$. The $\mathrm{CdS}_{\mathrm{x}} \mathrm{Se}_{1-\mathrm{x}}$ grains are not adhered to and penetrated each other. Therefore, even if one particle is exposed during ball milling, it will not affect the other chromogenic particles. This is close to the structure under the assumed conditions in the Lei's inclusion calculation model [20]. Under the same particle size, the effective inclusion rate of such structure will be much higher than that of traditional grains. However, some of the chromogenic particles of the traditional grains have been etched by acid to form the holes, and the size of the chromogenic particles is uneven, ranging from 20 to $300 \mathrm{~nm}$, as observed in Fig. 6c,d. Thus, after crushing, the surface area of the broken particles is larger, the $\mathrm{ZrSiO}_{4}$ coating layer is relatively thinner, and the large $\mathrm{CdS}_{\mathrm{x}} \mathrm{Se}_{1-\mathrm{x}}$ particles are more likely to be exposed. Once it is not successfully encapsulated by $\mathrm{ZrSiO}_{4}$, the entire particle will be eroded under high temperature or strong acid, and become invalid chromogenic particles. In addition, the particles prepared by the traditional process exist obvious agglomeration and penetration of the $\mathrm{CdS}_{\mathrm{x}} \mathrm{Se}_{1-\mathrm{x}}$ grains. Once the particles are exposed, other particles will be "linked". Therefore, when the average particle size of the traditional coating pigment is about $1.2 \mu \mathrm{m}$, there is no effective coating of chromogenic particles.

In liquid-phase synthesis, monoethanolamine and Hyperdispersant are added to alleviate the agglomeration phenomenon in the sol-precipitation system. Compared with the dispersion plan reported by Liu et al. [17], this synthesis strategy reduces the amount of ethanolamine and increases the amount of high-efficiency hyperdispersant solsperse 27000 . This is because when ethanolamine is excessive, the carbon element is not completely discharged during the firing process, and it is easy to be encapsulated in the crystal growth of $\mathrm{ZrSiO}_{4}$, leading to the darkening of the pigment and also affecting the inclusion efficiency. Ethanolamine has the function of complexing and anchoring metal ions (cadmium and zirconium), the latter mainly plays a steric resistance effect. With the cooperation of these two functions, it plays a key role in controlling the agglomeration of cadmium selenide and zirconium hydroxide, and controlling the uneven crystal growth, as suggested in Fig. 5 and Fig. 6. Furthermore, silicon can form 
gaseous silicon fluoride during the firing process, which has the ability of migration and homogenization. So long as zircon and cadmium selenide are well dispersed, the crystals grow uniformly, and the final $\mathrm{CdS}_{\mathrm{x}} \mathrm{Se}_{1-\mathrm{x}} @ \mathrm{ZrSiO}_{4}$ grains can grow according to the dispersion state of the precursor, and the inclusion rate and particle size are guaranteed.

In addition, raw materials are selected in this synthesis strategy, and the reactivity among various raw materials is well matched. If the activity of the precursor particles is too high, the chromogenic particles will grow up rapidly during firing, and the $\mathrm{ZrSiO}_{4}$ cannot quickly encapsulate it and cannot reach the ideal inclusion state. Simlarly, when the $\mathrm{ZrSiO}_{4}$ crystal grows too fast, the $\mathrm{CdS}_{\mathrm{x}} \mathrm{Se}_{1-\mathrm{x}}$ precursor crystal grows insufficient, and even if it is successfully encapsulated, the final pigment color will be dark. Therefore, the activity of the precursor is related to factors such as manufacturing process of the raw material, the content of impurities, and the types of impurities.

\section{Conclusions}

In this study, a set of technological schemes for effectively controlling the grain size and chromogenic particle size of the encapsulated pigment was explored in terms of the dispersibility of the sol system, the ration of material, the firing system, and the selection of raw materials. The size of developed inclusion pigment is uniform (200 $1000 \mathrm{~nm}$ ), and the size of the $\mathrm{CdS}_{\mathrm{x}} \mathrm{Se}_{1-\mathrm{x}}$ chromogenic particles is spherical $(20 \sim 100 \mathrm{~nm})$. Compared with the currently used red-brown and gold-brown ink-jet pigments, this pigment has the features of purer color, wider color range, and stronger color strength. Compared with traditionally encapsulated pigments, it has the advantages of good wear-resistance and color strength under the requirements of ink particle size. It can be completely used in the preparation of ink-jet red inks, which can replace the current commercially available red-brown, gold-brown, and praseodymium yellow pigments. It has a broad market prospect and can break the situation that traditionally included pigments cannot be used in ink-jet printing.

\section{Declarations}

\section{Acknowledgments}

This study was funded by the National Natural Science Foundation of China (51772136) and Jiangxi provincial key R\&D plan (20181ACE50017, 20192BBE50037, 20202BBE53011). The intellectual property rights belong to Jiangxi Jinhuan Pigment Co., Ltd.

\section{References}

1. Güngör GL, Kara A, Gardini D et al (2016) Ink-jet printability of aqueous ceramic inks for digital decoration of ceramic tiles. Dyes Pigm 127:148-154

2. Lee $\mathrm{JH}, \mathrm{Han} \mathrm{KS}$, Hwang $\mathrm{KT}$ et al. Recycling of steelmaking electric arc furnace dust into aqueous cyan ceramic ink for inkjet printing process and its printability. Ceram. Int. 2021, DOI: 
https://doi.org/10.1016/j.ceramint.2021.03.005

3. Yang LL, Zeng XJ, Ditta A et al (2020) Preliminary 3D printing of large inclined-shaped alumina ceramic parts by direct ink writing. J Adv Ceram 9:312-319

4. Pan ZD, Wang YM, Huang HN et al (2015) Recent development on preparation of ceramic inks in inkjet printing. Ceram Int 41:12515-12528

5. Dong WX, Bao QF, Gu XY et al (2015) Preparation of Fe-Cr-Zn-Al spinel brown pigments. China Ceram 51:58-61

6. Eppler RA (1977) Zirconia-based colors for ceramic glazes. Am Ceram Soc Bull 56:213-215

7. Eftekhari Yekta B, Tamizifar M, Rahimi N (2007) Synthesis of a zircon-cadmium sulfo selenide pigment by a sol-gel technique. J Ceram Soc Jpn 115:757-760

8. Zhang Y, Ye MQ, Han AJ et al (2018) Preparation and characterization of encapsulated $\mathrm{CoAl}_{2} \mathrm{O}_{4}$ pigment and charge control agent for ceramic toner via suspension polymerization. Ceram Int 44:20322-20329

9. Jiang WH, Xu XY, Chen T et al (2015) Preparation and chromatic properties of $\mathrm{C} @ Z \mathrm{ZSiO}_{4}$ inclusion pigment via non-hydrolytic sol-gel method. Dyes Pig 114:55-59

10. Chang QB, Wang X, Wang YQ et al (2014) Encapsulated carbon black prepared by sol-gel-spraying: A new black ceramic pigment. J Eur Ceram Soc 34:3151-3157

11. Peng C, Zhang CX, Lv M et al (2013) Preparation of silica encapsulated carbon black with high thermal stability. Ceram Int 39:7247-7253

12. Mao WX, Zhang W, Chi ZX et al (2015) Core-shell structured $\mathrm{Ce}_{2} \mathrm{~S}_{3} @ Z n O$ and its potential as a pigment. J Mater Chem A 3:2176-2180

13. Liu SG, Li YM, Wang ZM et al (2016) Enhanced high temperature oxidization resistance of silica coated $\mathrm{Y}-\mathrm{Ce}_{2} \mathrm{~S}_{3}$ red pigments. App Surf Sci 387:1147-1153

14. Yu SY, Wang DR, Liu Y et al (2014) Preparations and characterizations of $\mathrm{y}-\mathrm{Ce}_{2} \mathrm{~S}_{3} @ \mathrm{SiO}_{2}$ pigments from precoated $\mathrm{CeO}_{2}$ with improved thermal and acid stabilities. RSC Adv 4:23653-23657

15. Hosseini-Zori M (2013) Substitution of a fraction of zircon by cristobalite in nano hematite encapsulated pigment and examination of glaze application. J Adv Ceram 2:149-156

16. Chen SL, Cheng MT, Lang $Y$ et al (2019) Preparation and characterization of monodispersed spherical $\mathrm{Fe}_{2} \mathrm{O}_{3} @ \mathrm{SiO}_{2}$ reddish pigments with core-shell structure. J Adv Ceram 8:39-46

17. Liu HF, Dai WB, Wang H et al (2015) Study on the preparation of the $\mathrm{CdS}_{\mathrm{x}} \mathrm{Se}_{1-\mathrm{x}} @ \mathrm{ZrSiO}_{4}$ red ceramic pigments and its properties. J Sol-Gel Sci Technol 75:198-205

18. Peymannia M, Soleimani-Gorgani A, Ghahari M et al (2015) The effect of different dispersants on the physical properties of nano $\mathrm{CoAl}_{2} \mathrm{O}_{4}$ ceramic ink-jet ink. Ceram Int 41:9115-9121

19. Zhang $\mathrm{Y}$, The study of $\mathrm{ZrSiO}_{4}-\mathrm{Cd}\left(\mathrm{S}_{\mathrm{x}} \mathrm{Se}_{1-\mathrm{x}}\right)$ pigments synthesized by sol and co-precipitation method. Xiangtan University (2006) 
20. Lei BL (2013) An overview of the study on $\mathrm{CdS}_{x} \mathrm{Se}_{1-\mathrm{x}} @ \mathrm{ZrSiO}_{4}$ as brilliant red heteromorphic pigments. China Ceram 52:4-10

Figures

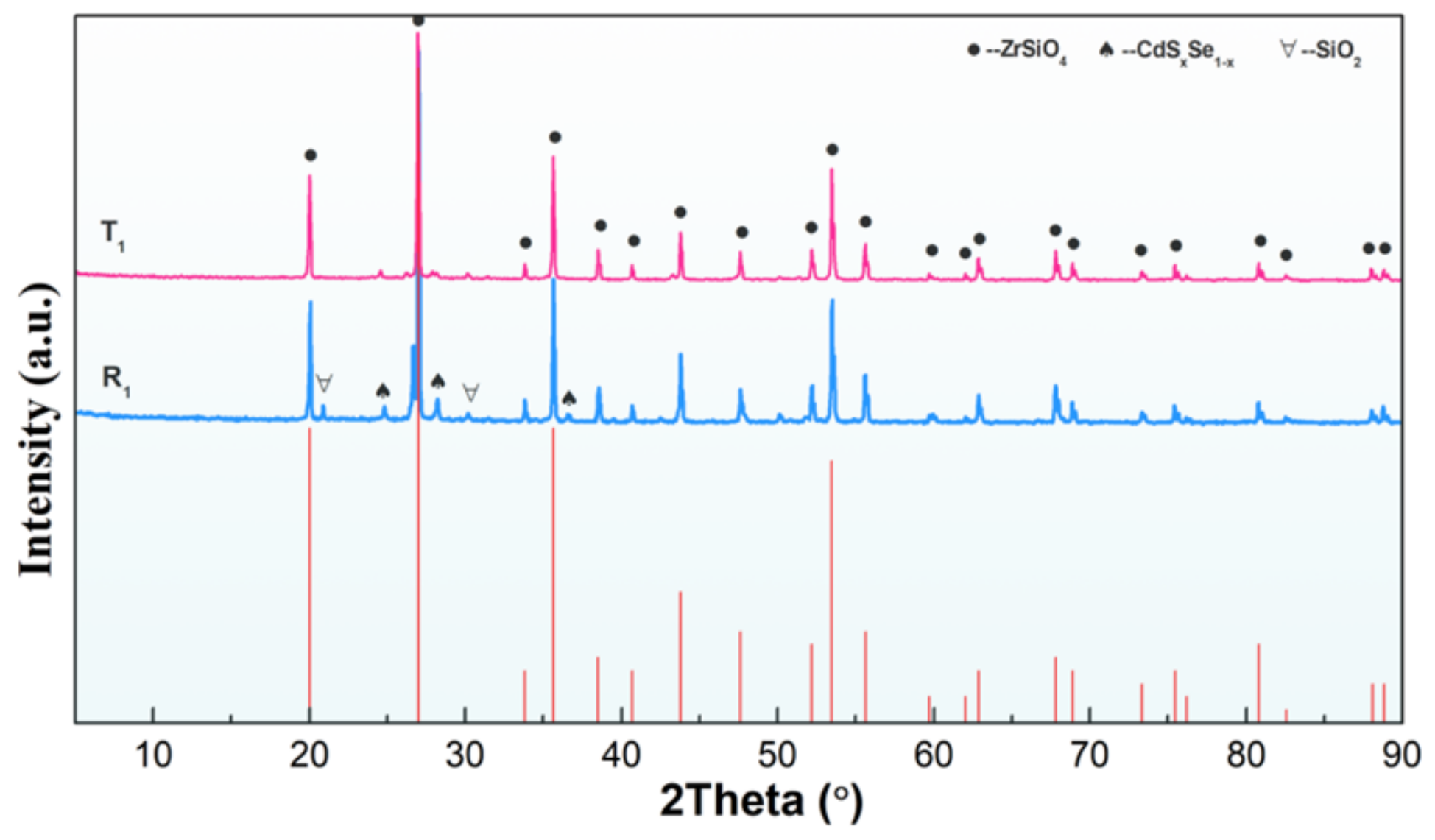

Figure 1

XRD patterns of red pigments $\mathrm{R} 1$ and $\mathrm{T} 1$. 

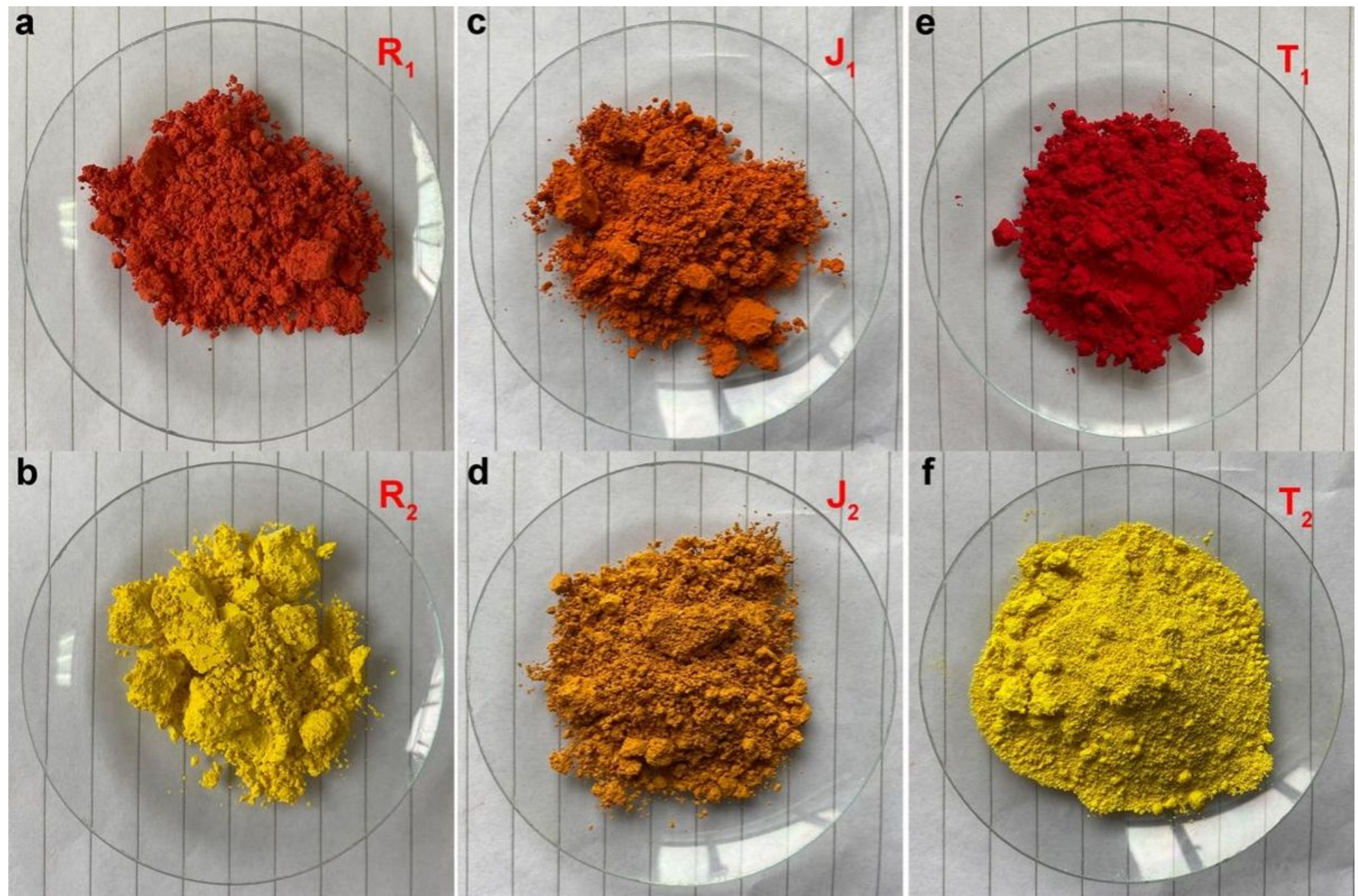

Figure 2

Optical photographs of pigments R1 (a), R2 (b), T1 (c), T2 (d), J1 (e), and J2 (f).

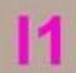

12

13

14

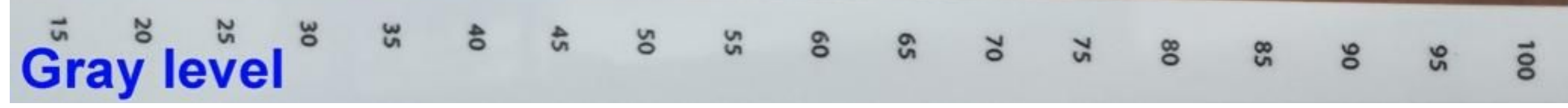

Figure 3

Optical photographs of inks 11,12 , I3, and 14 after firing. 


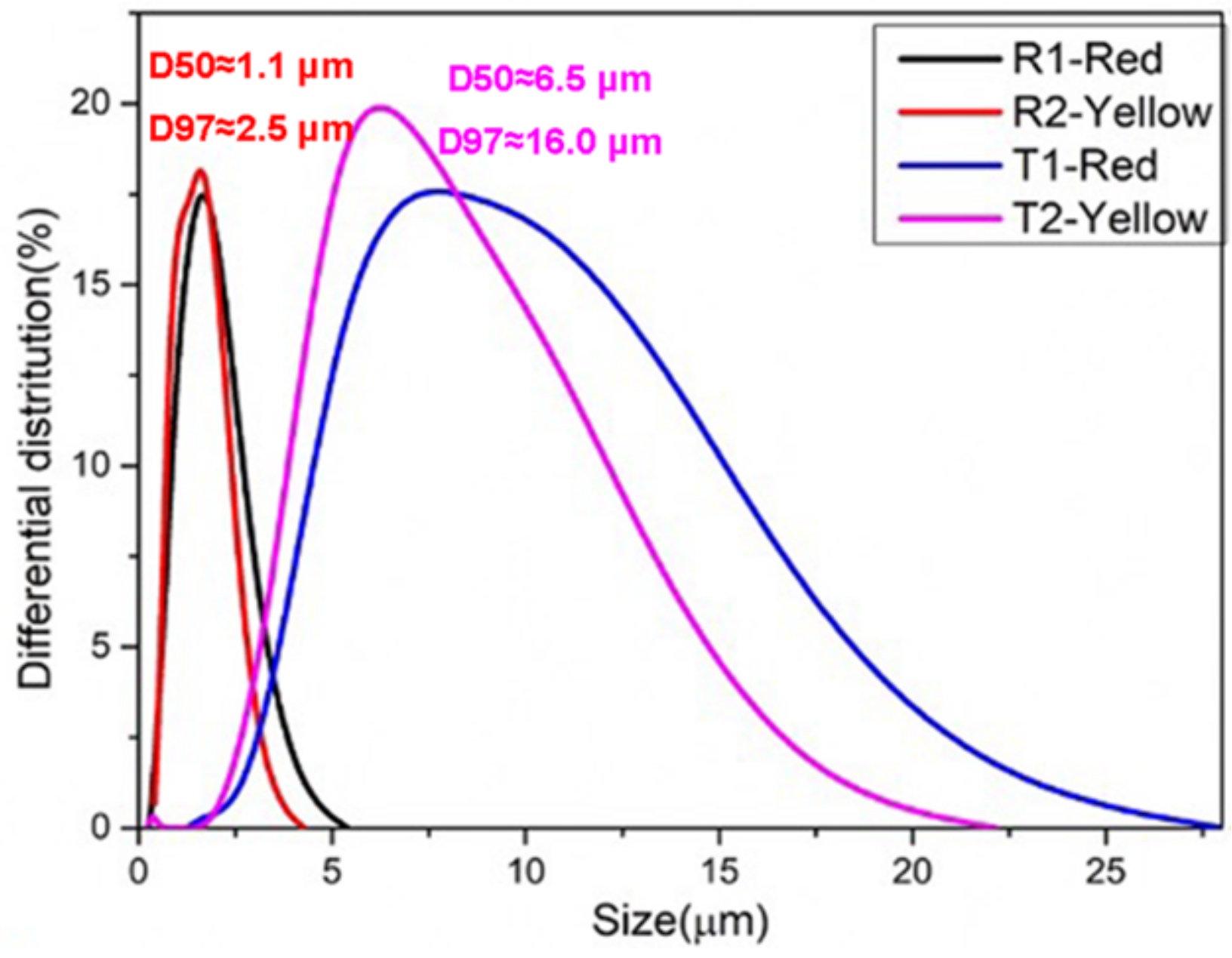

Figure 4

Grain size distribution of pigments R1, R2, T1, and T2. 

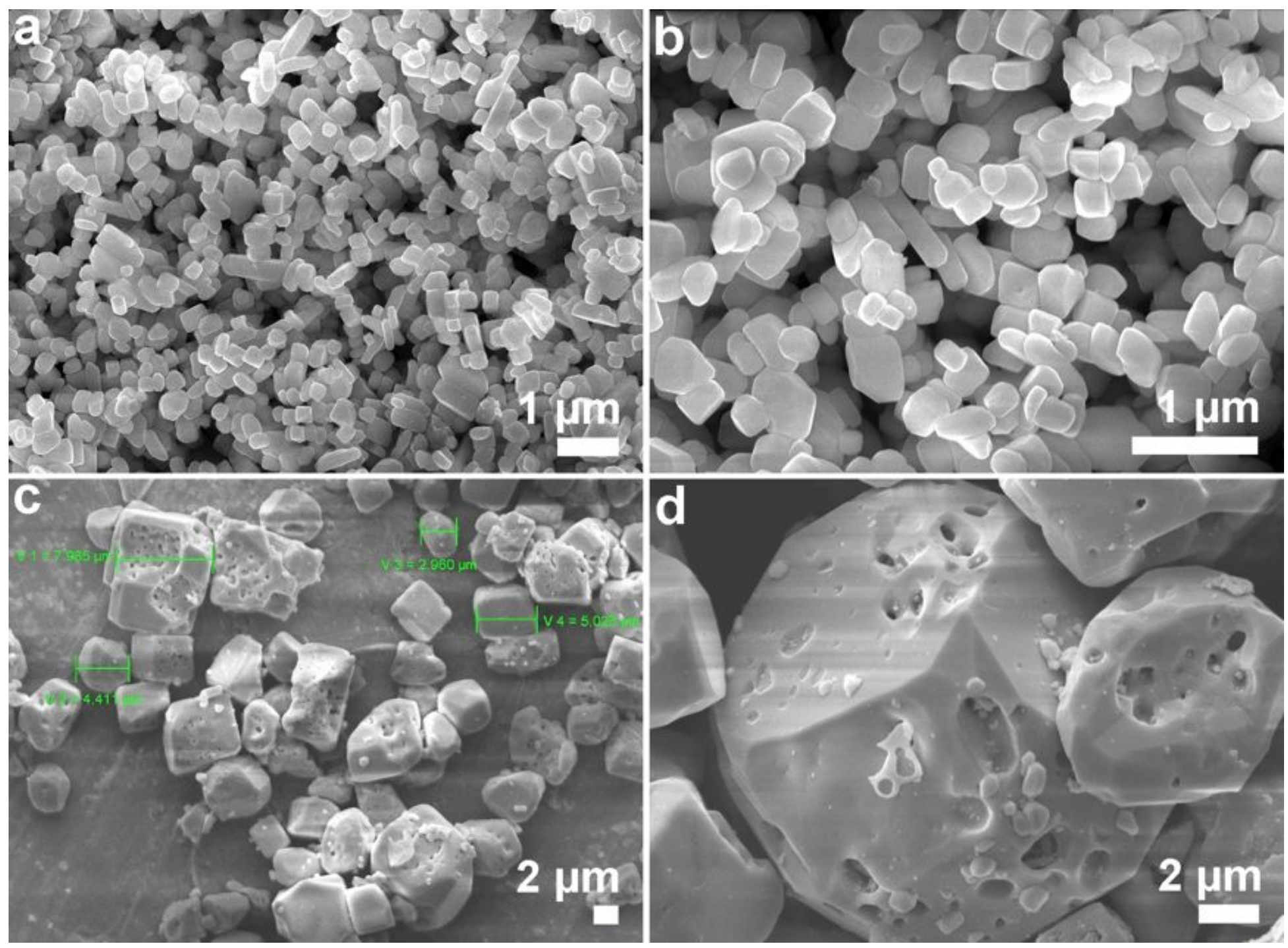

Figure 5

SEM images of pigments R1 $(a, b)$ and $T 1(c, d)$. 


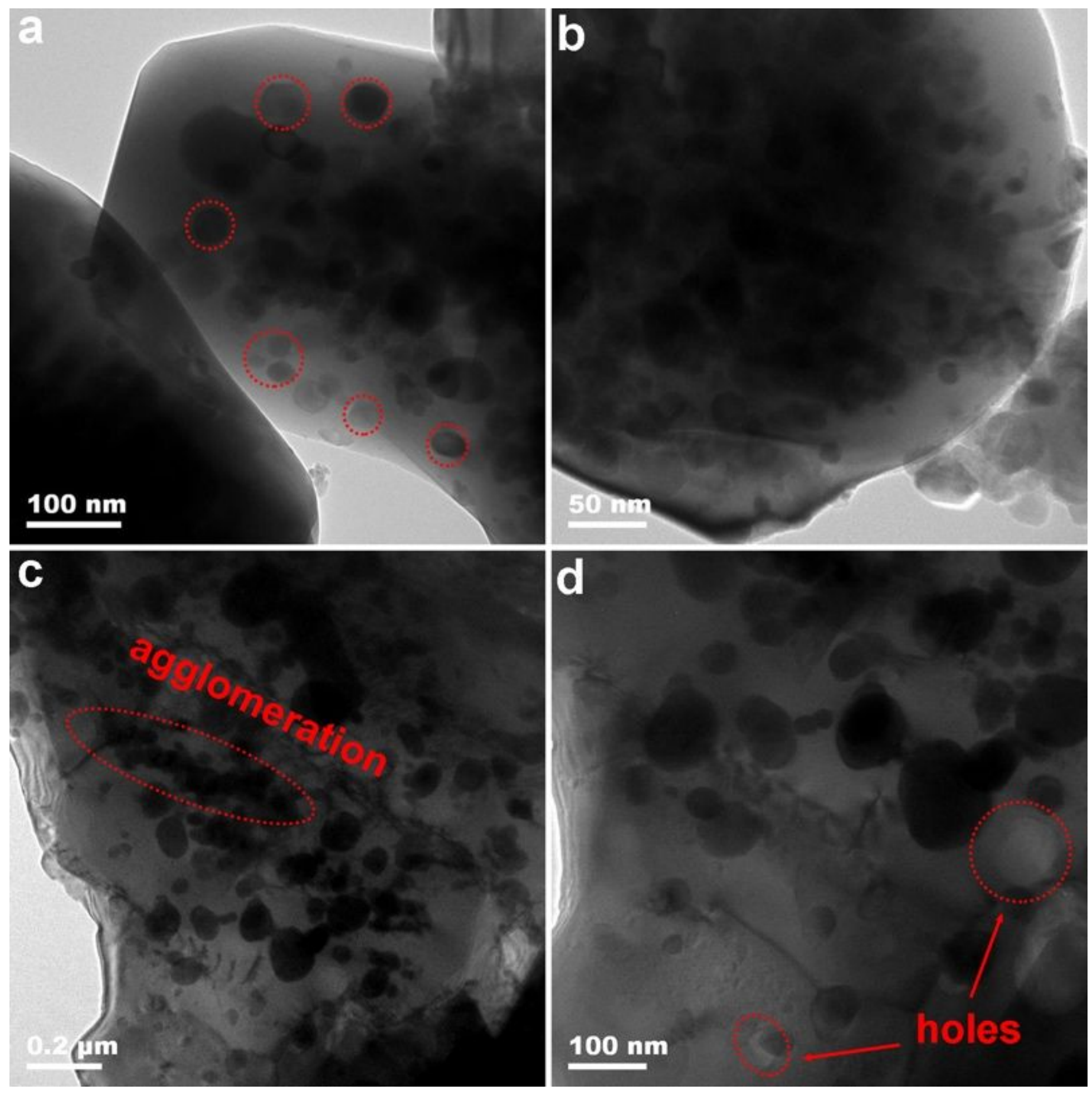

Figure 6

TEM images of pigments R1 $(a, b)$ and $\mathrm{T} 1(\mathrm{c}, \mathrm{d})$. 